\title{
The Concept of a Rupture Risk Envelope for the Cochleo-Saccular Membranes
}

\author{
Daniel J. Pender ${ }^{1}$ (D) \\ ${ }^{1}$ Department of Otolaryngology, Columbia University, New York City, \\ NY, United States. \\ Address for correspondence Daniel J. Pender, MSE, MD, FACS, 145 \\ West 86th Street, \#1C, New York City, NY 10024, United States \\ (e-mail:djp2@cumc.columbia.edu).
}

Int Arch Otorhinolaryngol 2022;26(4):e561-e565.

\begin{abstract}
Keywords

- Meniere disease

- vestibular science

- Reissner membrane
\end{abstract}

\section{Introduction}

Meniere disease was first described in 1861, and is a clinical entity characterized by hearing loss, tinnitus and vertigo. ${ }^{1}$ The associated pathology known as endolymphatic hydrops was first described in $1938 .^{2}$ The pathophysiology is sus- pected to entail rupture of the labyrinth membranes, especially the thin and delicate cochleo-saccular membranes of the pars inferior portion. These cochleo-saccular membranes consist of a single basement membrane, less than 5 microns thick, covered on both sides by a single layer of epithelial cells. Rupture of these membranes causes the release of received

February 6, 2021 accepted after revision

October 20, 2021

published online

February 4, 2022
DOI https://doi.org/ 10.1055/s-0042-1742331. ISSN 1809-9777.

\footnotetext{
(C) 2022. Fundação Otorrinolaringologia. All rights reserved.

This is an open access article published by Thieme under the terms of the Creative Commons Attribution-NonDerivative-NonCommercial-License, permitting copying and reproduction so long as the original work is given appropriate credit. Contents may not be used for commercial purposes, or adapted, remixed, transformed or built upon. (https://creativecommons.org/ licenses/by-nc-nd/4.0/) Thieme Revinter Publicações Ltda., Rua do Matoso 170, Rio de Janeiro, RJ, CEP 20270-135, Brazil
} 
potassium-rich endolymph into the surrounding perilymph with a neurotoxic effect. ${ }^{3}$ The etiology remains enigmatic but may involve heredity, auto-immunity, and inflammation. ${ }^{4}$

The reason why some membranes in Meniere disease only distend while others rupture remains enigmatic. A doublehit mechanism that involves a change in membrane distensibility is theorized to play a role in this process. ${ }^{5}$ However, the biomechanics of how this might come about remained speculative. Recent investigations suggest that hydropic lesion behavior may be determined by the viscoelastoplastic properties of cochleo-saccular membranes, especially the sensitivity to strain rate. ${ }^{6}$ The aim of this study is the construction of a rupture risk envelope for the cochleosaccular membranes, based on viscoelastoplasticity, to provide insight into the lesion behavior in Meniere disease.

\section{Methods}

A model membrane consisting of precipitated collagen was used to emulate the cochlea-saccular membranes. ${ }^{6}$ The reported deformation data from this collagen model of the cochlea-saccular membranes was utilized in this analysis. ${ }^{7}$ The onset of rupture risk was defined as the yield point of a collagen model membrane when subjected to in vitro tensile testing. The yield point is defined as the point where the load deformation curve starts to flatten, indicating incipient membrane failure. This yield point stress was defined as $80 \%$ of the reported failure stress on the load deformation curve, as shown in - Fig. 1, and used with permission. ${ }^{7}$ The yield point stress was correlated with reported strain rate and linear modulus data used for the collagen model. This locus of yield points was then plotted on a Cartesian loaddeformation grid to graphically construct the rupture risk envelope.

\section{Results}

- Table 1 presents the calculated yield point data for a collagen model of the cochleo-saccular membranes. These

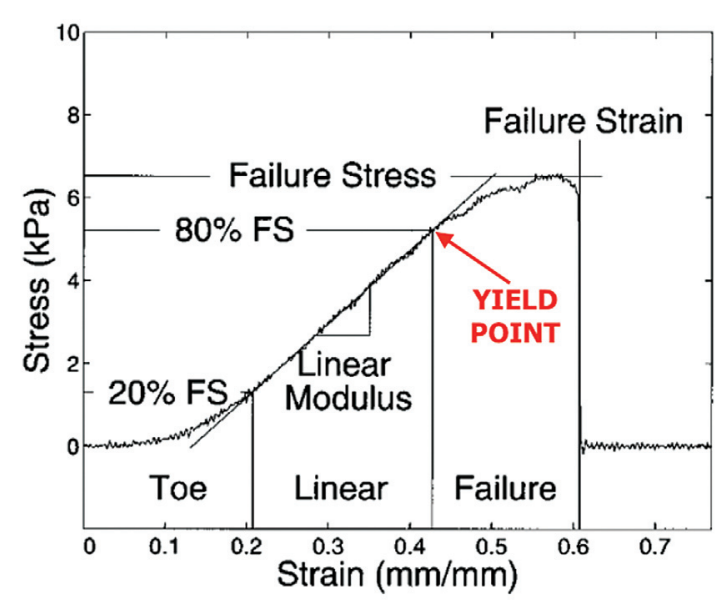

Fig. 1 Model's load-deformation curve, with yield point indicated as $80 \%$ of failure stress. Source: Roeder et al. ${ }^{7}$.
Table 1 Calculated yield stress for each strain rate and linear modulus based on reported data for a mesh membrane of precipitated collagen

\begin{tabular}{|l|l|l|}
\hline $\begin{array}{l}\text { Strain rate } \\
\% / \text { minute }\end{array}$ & $\begin{array}{l}\text { Linear modulus } \\
\mathrm{kPa} / \%\end{array}$ & $\begin{array}{l}\text { Yield stress } \\
\mathrm{kPa}\end{array}$ \\
\hline 19.2 & 15.7 & 4.3 \\
\hline 38.5 & 16.6 & 4.8 \\
\hline 192.0 & 20.9 & 6.1 \\
\hline 385.0 & 25.0 & 7.0 \\
\hline
\end{tabular}

values are derived from reported strain rate and linear modulus data from a mesh membrane of precipitated collagen. ${ }^{7}$ This shows that at the highest reported strain rate of $385 \%$ per minute, the linear modulus is high $(25 \mathrm{kPa} /$ per unit of strain), and an early yield point at $30 \%$ strain is reached at elevated stress $(7.0 \mathrm{kPa})$. In contrast, at the lowest reported strain rate of $19.2 \%$ per minute, the stress mounts more slowly as strain proceeds to $44 \%$ and the membrane yields at a lower stress $(4.3 \mathrm{kPa})$. Thus, higher strain rate is associated with higher membrane stress and earlier onset of incipient membrane failure.

The rupture risk envelope defined by the locus of yield points is shown in - Fig. 2. This rupture risk envelope exhibits a downward sloping pattern as the strain rate decreases. The dotted lines - Fig. 2 also show the projected behavior of the risk envelope at strain rates above and below those reported.

\section{Discussion}

Summary of Results: The concept of a rupture risk envelope arises from the locus of membrane yield points at different strain rates. The yield point is essentially the dividing line between terminal zone of linear membrane distention and the onset of exaggerated membrane distention that portends rupture. The rupture risk envelope graphically encapsulates

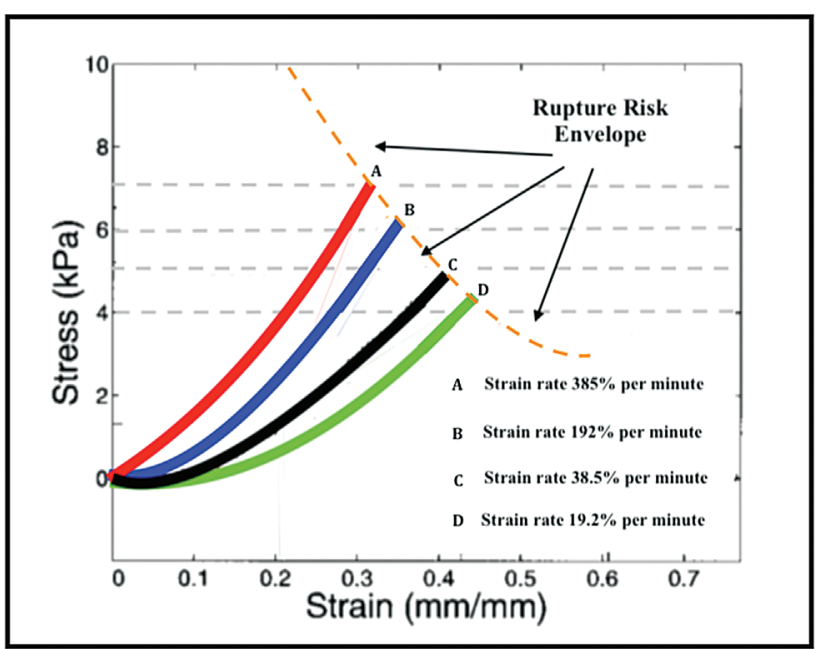

Fig. 2 The rupture risk envelope, as the locus of membrane yield points at various strain rates. 
the variation in distensibility of the membrane at different strain rates.

Analysis of Results: All membranes will distend when stressed and will rupture if sufficiently strained. Strain rate is known to be a dynamic factor that appears to play a significant role in the timing of rupture risk. Higher strain rates are associated with less distention and earlier failure, while lower rates afford greater distention before failure.

Membrane strain behavior appears to be determined by two main factors: the character of the applied force and the nature of the material resistance. The character of the applied force refers to the manner in which the specimen is stressed. When force is applied to a membrane specimen in vitro by a mechanical tensometer, as shown schematically in - Fig. 3 and used with permission, ${ }^{7}$ the strain rate can be controlled with precision. The stress and strain induced in the specimen can also be measured directly and simultaneously with great accuracy by means of calibrated sensors. However, when force is to be applied in vivo, (by mechanical indentation or by hydraulic injection pressure), strain rate, stress and strain cannot be measured directly. Instead, these parameters must be estimated via a calculation that depends on the size, shape, and wall thickness of the membranous chamber. ${ }^{8}$ These considerations suggest that in vitro tensometric testing is the preferred reference standard for determining the load-deformation characteristics of this biological tissue.

The nature of material resistance refers to the factors that control membrane reaction to applied force. These factors include collagen's architecture, fiber density, and molecular behavior. Collagen architecture refers to the geometric organization of the collagen fibrils. This can vary greatly, from highly aligned collagen bundles that offer a stiffer resistance to stretching (e.g., human tendon) to loose mesh-like collagen fibers that offer a more lax resistance (e.g., skin basement membrane). ${ }^{9}$ And these responses are not fixed but can be modulated by the rate at which the tissue is stretched, ${ }^{10}$ as noted below.

Collagen fiber density has a demonstrable effect on elastic modulus. Collagen concentration appears to have a linear

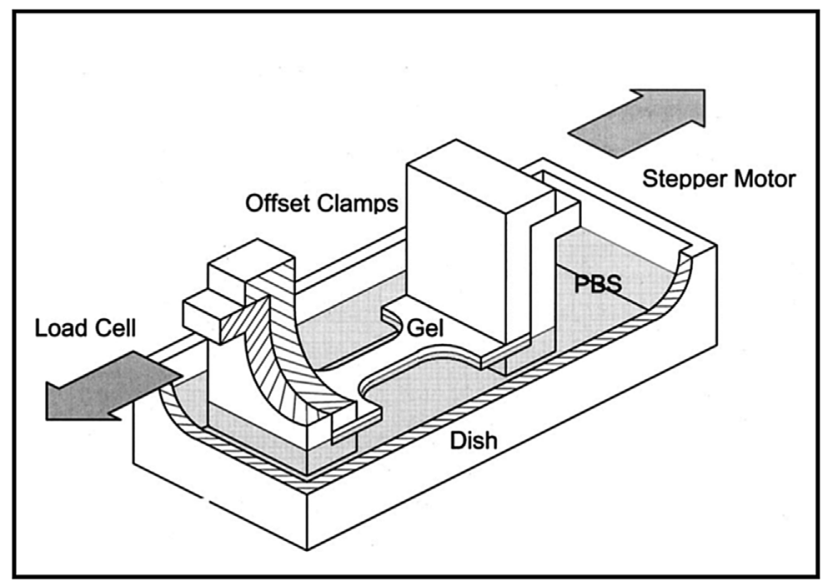

Fig. 3 Schematic of the in vitro tensometric testing of a membranous collagen gel specimen submerged in a physiologic bath solution. Source: Roeder et al. ${ }^{7}$ relation to both elastic modulus and rupture stress. ${ }^{7}$ This implies that an increased collagen fiber density will strengthen a membrane while a loss of fiber density will weaken it.

Collagen's molecular behavior is dependent on temperature and strain rate. These features are interactive, in that one can aggravate or mitigate the other. Thus both temperature and strain rate need to be controlled in specimen testing. If the specimen temperature is too low, it causes collagen to fracture in a brittle, glass-like manner. At an intermediate temperature, known as the glass transition temperature, $\mathbf{T}_{\mathbf{G}}$, collagen will exhibit what is described as a leathery viscoelastic behavior, with some limited distention, before fraying and shredding, which leads to full rupture. At higher temperatures, it will exhibit a more rubbery and stringy distention before finally rupturing. ${ }^{9}$ In mammals, tissue collagens generally have a glass transition temperature $\mathbf{T}_{\mathbf{G}}$ of $35^{\circ} \mathrm{C}$, which is close to body temperature, ${ }^{11}$ suggesting that collagen in vivo will exhibit a leathery viscoelastic behavior. Thus, in vitro tensometer testing should be performed with the specimen in a bath of physiologic fluid set at body temperature, to control the effect of temperature on tissue behavior.

The effect of temperature on collagen's behavior described above can be mimicked by strain rate effects. ${ }^{10}$ High strain rates favor brittle, glasslike rupture, with less distention akin to low temperature effects; intermediate strain rates favor a leathery response, with moderate distention and shredding; and low strain rates tend to produce a more pronounced distention with a stringy type of failure. It should be noted that strain rate sensitivity is not a linear function. Below a certain threshold, strain rate has no apparent effect on load-deformation characteristics. Only above this threshold does it come into play. ${ }^{9}$ Accordingly, optimal tissue testing should encompass a range of strain rates to determine the strain rate threshold and the effect of higher strain rates on the tissue in question. It should also be noted that as strain rate increases, the toe region of the typical sigmoid viscoelastoplastic response curve progressively diminishes and virtually disappears. This implies that at the high strain rates, the stress buffer provided by the very distensible toe region is lost. This loss of the toe region accounts for the rigid and brittle behavior of the polymer at high strain rate. ${ }^{9}$

Comparison of Results with Published Data: The concept of a membrane rupture risk envelope reported herein is consistent with the results of creep testing. In polymer creep testing, variable amounts of strain are imposed almost instantaneously at time $=0$. With low degrees of imposed strain and associated low stress levels, a polymer may be able to distend considerably before rupture. When high degrees of strain are imposed instantaneously with associated high stress, the material tends to rupture acutely. Such data permit construction of a creep rupture envelope for polymers. $^{12}$

Commentary on Methodology and Limitations: This study assumes that raised endolymphatic pressure is the driving force behind displacement of the cochlea-saccular membranes. Some studies have failed to document an elevated 
endolymphatic pressure acting on the membranous labyrinth in experimental hydrops in Guinea pigs. ${ }^{13}$ Others have noted that experimental infusions into the endolymph have raised pressure in both endolymph and perilymph, but without a measureable differential between them. ${ }^{14}$ Such findings may be a reflection of the fact that these membranes are especially pliant at low initial pressure, as indicated by the 'toe' region of the viscoelastoplastic load deformation curve in -Fig. 1. This figure indicates that substantial membrane deformation can occur at pressures that are near zero.

Furthermore, this study focuses exclusively on the cochlea-saccular membranes. The model collagen membrane described herein is devoid of epithelial cells. Epithelial cells have been shown to increase the mechanical resistance of an artificial skin, consisting of collagen covered with layers of epithelial cells. This is thought to reflect the presence of a cytoskeleton network of actin and microtubules within the several cellular layers. ${ }^{15}$ However the Reissner membrane has only a single layer of epithelial cells on each surface, and the extent to which it alters the mechanical behavior of the collagen basement membrane is uncertain. It is, however, known that the intercellular adhesions give way before the Reissner collagen membrane itself fails, suggesting that the basement membrane is carrying most of the load. ${ }^{16}$

It has been shown that these membranes are substantially weaker than the pars superior membranes ${ }^{17}$ and can, therefore, be more susceptible to pressure-induced displacement. This is in accord with a biomechanical analysis that quantified the heightened stress proclivities in the cochlea-saccular membranes compared with those in the thicker pars superior membranes. ${ }^{8}$ It is also consistent with the findings that in Meniere disease the hydropic lesions always occur initially in the cochleasaccular membranes. ${ }^{18}$

Additionally, while certain genes are suspected to play a structural role in Meniere disease, this study is focused exclusively on the rupture risk behavior of the collagen membrane model itself. Potential contributions to the development of Meniere disease by genetic factors such as the OTOG gene are beyond the scope of this study. ${ }^{19}$

Finally, this study focuses on the early phase of the hydropic process in the cochlea and saccule membranes, and the initial potential for rupture therein, based on biomechanics. What happens to these membranes in later stages of the disease, when damage is more extensive and has spread to the pars superior, is beyond the scope of the current study.

\section{Conclusions}

The concept of a rupture risk envelope is presented for a model of the cochleo-saccular membranes. This concept helps to explain how variations in membrane distensibility might occur, as suspected in the double-hit theory of lesion generation in Meniere disease. This suggests that membrane lesion behavior in Meniere disease is not a simple static entity but instead represents a spectrum of responses that depend on certain dynamic factors. These include not only the rate and degree of force applied to the membrane, but also the membrane's viscoelastoplastic behavior. Membrane viscoelastoplasticity hinges on the membrane's collagen architecture, fiber density, and molecular behavior, which, in turn, control its strain rate characteristics and propensity for failure. The concept of a rupture risk envelope encompasses all of these various response elements to provide insight into acute membrane failure, chronic membrane distention, and various intervening combinations.

\section{Presented at}

International Otopathology Society.

Harvard Medical School.

Boston, Massachusetts, June 11, 2019.

\section{Funding Sources}

None.

Conflict of Interests

The author has no conflict of interests to declare.

\section{References}

1 Menière P. Mémoire Sur Des Lésions De L'oreille Interne Donnant Lieu À Des Symptômes De Congestion Cérébrale Apoplectiforme. Gazette Méd Paris 1861;16:597-601

2 Hallpike CS, Cairns H. Observations on the Pathology of Ménière's Syndrome: (Section of Otology). Proc R Soc Med 1938;31(11): 1317-1336

3 Schuknecht HF. Ménière's disease, pathogenesis and pathology. Am J Otolaryngol 1982;3(05):349-352

4 Perez-Carpena P, Lopez-Escamez JA. Current Understanding and Clinical Management of Meniere's Disease: A Systematic Review. Semin Neurol 2020;40(01):138-150

5 Pender DJ. The Biomechanics of Lesion Formation in Endolymphatic Hydrops: Single and Double Hit Mechanisms. Otol Neurotol 2019;40(03):398-403

6 Pender DJ. A model of viscoelastoplasticity in the cochleo-saccular membranes. Laryngoscope Investig Otolaryngol 2019;4(06): 659-662

7 Roeder BA, Kokini K, Sturgis JE, Robinson JP, Voytik-Harbin SL. Tensile mechanical properties of three-dimensional type I collagen extracellular matrices with varied microstructure. J Biomech Eng 2002;124(02):214-222

8 Pender DJ. Membrane stress proclivities in the Mammalian labyrinth. Int Arch Otorhinolaryngol 2014;18(04):398-402

9 Sherman VR, Yang W, Meyers MA. The materials science of collagen. J Mech Behav Biomed Mater 2015;52(12):22-50

10 Arumugam V, Naresh MD, Somanathan N. Effect Of Strain Rate On The Fracture Behavior Of Collagen. J Mater Sci 1992;27(01): 2649-2652

11 Sarti B, Scandola M. Viscoelastic and thermal properties of collagen/poly(vinyl alcohol) blends. Biomaterials 1995;16(10): 785-792

12 Dept of Mech Engineering, University of Minnesota. Long Term Performance of Polymers. (Cited May 22,2021). Available from https://docplayer.net/11405026-Long-term-performance-ofpolymers.html

13 Warmerdam TJ, Schröder FHHJ, Wit HP, Albers FWJ. Perilymphatic and endolymphatic pressures during endolymphatic hydrops. Eur Arch Otorhinolaryngol 2003;260(01):9-11 
14 Takeuchi S, Takeda T, Saito H. Pressure relationship between perilymph and endolymph associated with endolymphatic infusion. Ann Otol Rhinol Laryngol 1991;100(03): 244-248

15 Ionescu AM, Chato-Astrain J, Cardona Pérez JC, et al. Evaluation of the optical and biomechanical properties of bioengineered human skin generated with fibrin-agarose biomaterials. J Biomed Opt 2020;25(05):1-16

16 Shinozaki N, Kimura RS. Scanning electron microscopic observations on the distended Reissner's and saccular mem- branes in the guinea pig. Acta Otolaryngol 1980;90(56):370-384

17 Yamamoto N, Ishii T. Mechanical properties of membranous labyrinths measured with a microtension tester. Acta Otolaryngol Suppl 1991;481:80-82

18 Pender DJ. Endolymphatic hydrops and Ménière's disease: a lesion meta-analysis. J Laryngol Otol 2014;128(10):859-865

19 Roman-Naranjo P, Gallego-Martinez A, Soto-Varela A, et al. Burden of Rare Variants in the OTOG Gene in Familial Meniere's Disease. Ear Hear 2020;41(06):1598-1605 